This item was submitted to Loughborough's Research Repository by the author.

Items in Figshare are protected by copyright, with all rights reserved, unless otherwise indicated.

\title{
Making alumina microcomponents from Al powder
}

PLEASE CITE THE PUBLISHED VERSION

http://www.scientific.net

PUBLISHER

(c) Trans Tech Publications

VERSION

AM (Accepted Manuscript)

LICENCE

CC BY-NC-ND 4.0

REPOSITORY RECORD

Kim, Jung-Sik, Kyle Jiang, C.L. Falticeanu, G.J. Davies, and Isaac T. Chang. 2012. "Making Alumina Microcomponents from Al Powder". figshare. https://hdl.handle.net/2134/11223. 
This item was submitted to Loughborough's Institutional Repository (https://dspace.lboro.ac.uk/) by the author and is made available under the following Creative Commons Licence conditions.

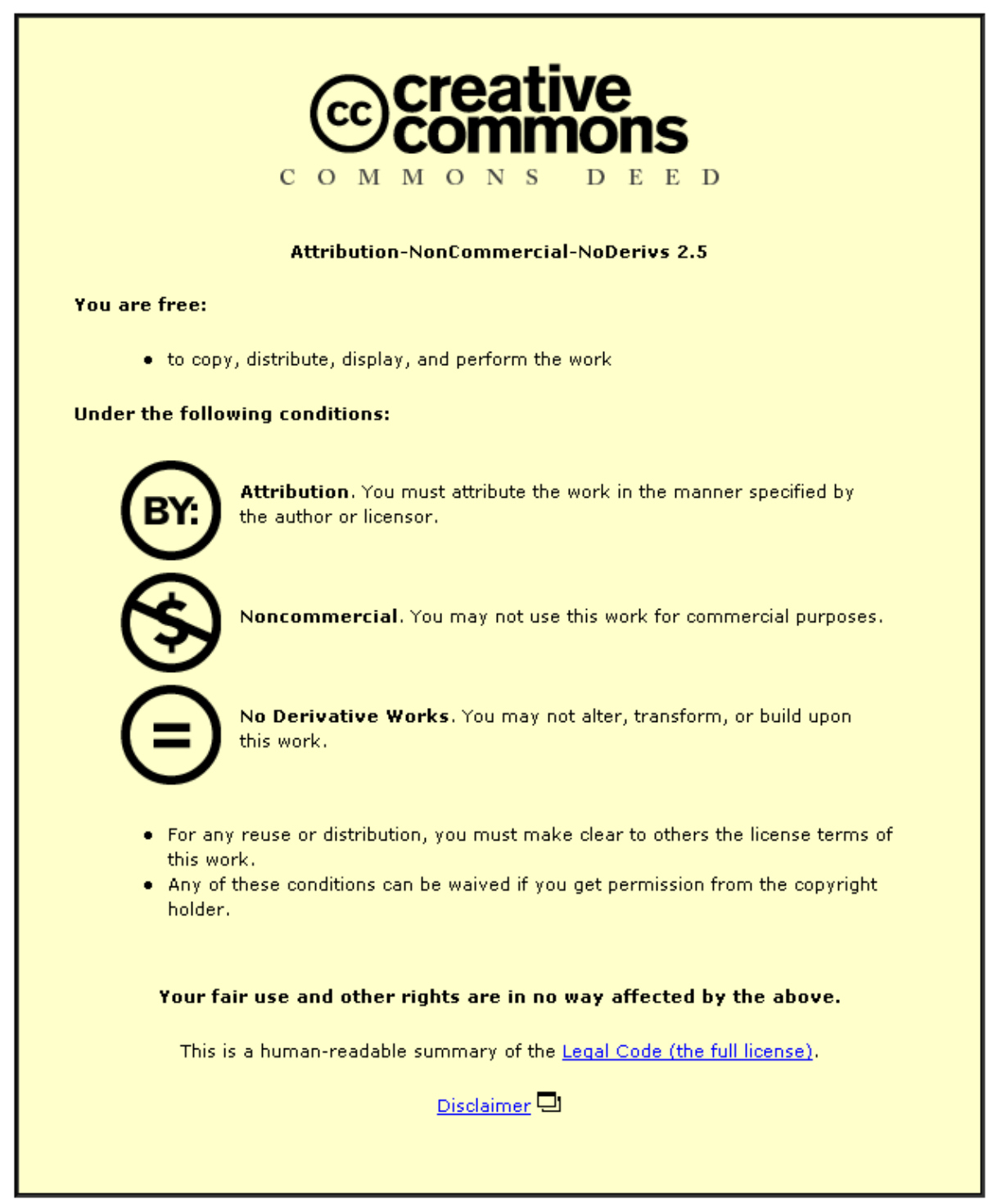

For the full text of this licence, please go to: http://creativecommons.org/licenses/by-nc-nd/2.5/ 


\author{
Making Alumina Microcomponents From Al Powder \\ J.S. Kim ${ }^{1, a}$, K. C. Jiang ${ }^{1, b}$, L. Falticeanu ${ }^{2, c}$, G. J. Davies ${ }^{d}$, I. Chang ${ }^{2, e}$ \\ School of Engineering \\ ${ }^{1}$ Mechanical and Manufacturing Engineering, \\ ${ }^{2}$ Metallurgy and Materials School of Engineering, \\ University of Birmingham, Birmingham, UK, B15 2TT \\ ajsk238@bham.ac.uk, bk.c.jiang@bham.ac.uk, 'lucianfalticeanu@yahoo.co.uk, \\ 'G.J.Davies@bham.ac.uk, i.t.chang@bham.ac.uk
}

Keywords: alumina microcomponent, micro-moulds, ultrafine Al powder, sintering.

\begin{abstract}
Alumina microcomponents have distinguishing advantages over $\mathrm{Si}$ counterparts. However, the shrinkage of alumina, as high as $20 \%$, makes it difficult to produce precision components that require a high tolerance. A new fabrication process is presented to greatly reduce the shrinkage. The process consists of forming an Al powdered component through sintering and transforming the Al powdered component into an alumina part. In this way, the shrinkage occurring in sintering the $\mathrm{Al}$ powder component will be compensated by the expansion occurred when $\mathrm{Al}$ transforms into alumina. The process involves producing micro-moulds, preparing metallic paste, filling the micro-moulds with the metallic paste, demoulding, sintering the green Al patterns and finally oxidising the sintered Al-based components to achieve alumina components. The process was proven successful. Characterization of the sintered alumina microcomponents has been undertaken, including SEM image analysis, density and scale measurements.
\end{abstract}

\title{
Introduction
}

Alumina has very good thermal, mechanical and chemical inertness properties, which make it suitable for applications in high temperature, high pressure and chemical corrosion conditions. The piezoelectric or electro-optical properties offer alumina a lot of applications including MEMS [1]. Present micro ceramic fabrication techniques come from traditional integrated circuit (IC) technologies, where wet etching [2] and dry etching [3] are the main approaches. But stable mask material that can withstand the aggressive etching conditions is a prerequisite for such etching processes. Chemical vapour deposition (CVD) is another way to grow ceramic film on a wafer. However, it is difficult to obtain high aspect ratio and thick structures using CVD due to its planar nature of the process. Screen printing can be used to pattern thicker micro patterns, but its lateral resolutions are generally limited to $100 \mu \mathrm{m}$. There are also some techniques which are scaled down from the current ceramic forming techniques, such as co-extrusion [4], slip casting [5], rapid prototyping [6,7] and selective laser sintering (SLS) [8,9]. Although the above mentioned techniques are in development and in use, they are limited by the small dimensions they can be applied to. For example, a pressure assisted slip casting was used for the micro fabrication of columns and nozzles of $10 \mu \mathrm{m}$ size and high aspect ratio, but only suitable for thin wall thickness structures and disk-like substrates [10].

The sintering process is widely used in both ceramics and metallic powder injection moulding process and can also be used in microcomponent fabrication. Some researchers used photoresist structures [11], such as using deep SU-8 moulds, to make moulds for forming patterns from powder suspension or powder polymer precursor. It is usually combined with the mould releasing method to extract the structures by either pyrolysis decomposition or chemical dissolution of the photoresists $[1,11]$. The technique presented in this research combines both high resolution features patterning technique using photolithography and the simplicity of a suspension-based powder deposition 
technique. By combining the Ultra-Thick SU-8 Process (UTSP) and micro-moulding process, a new novel process for microfabrication is developed.

The research work presented in this paper is set up to combine $\mu$ PIM, powder sintering technology and MEMS technology together in order to develop a new process of producing 3D metallic microcomponents. In this study, a new approach is employed to achieve near shrinkage free sintered microcomponents using loosely packed powders. This approach consists of fabricating aluminium components first, then transforming these shaped aluminium components into alumina parts. In the process, high quality soft micromoulds are fabricated using MEMS technology, and a pressure free sintering process is developed for micro $\mathrm{Al}$ and nano $\mathrm{Cu}$ powder mixture. The process can be used with the soft moulds to produce 3D metallic microcomponents. The process can be summarized as: (1) production of master moulds in SU-8 or Si; (2) production of polydimethylsiloxane (PDMS) soft moulds from the masters; (3) mixing micro-sized Al and nanosized $\mathrm{Cu}$ powders with an adhesive binder; (4) filling the moulds with the powder mixture; (5) demoulding to produce the green components; (6) sintering of green components to produce the Albased microcomponents; and (7) heating this component over $1450^{\circ} \mathrm{C}$ in air for oxidization of $\mathrm{Al}$ into $\mathrm{Al}_{2} \mathrm{O}_{3}$.

\section{Experimental procedure}

Mould fabrication. The fabrication process to produce net shape microcomponents using $\mathrm{Al}$ alloy powder starts from making master moulds and the UTSP has been used in this step. In producing $1 \mathrm{~mm}$ thick microstructures, SU-8 50 (Microchem, USA) is cast on to a well levelled wafer and baked at $65^{\circ} \mathrm{C}$ for $2 \mathrm{hrs}$, and then at $95^{\circ} \mathrm{C}$ for $15 \mathrm{hrs}$. Afterwards, the baked SU-8 is exposed under UV light at $2.5 \mathrm{~J} / \mathrm{Cm}^{2}$. The wafer is baked again at $65^{\circ} \mathrm{C}$ for 15 minutes and then at $90^{\circ} \mathrm{C}$ for 25 minutes before being fully developed in EC solvent supplied by Chestech, UK. More details can be found in references $[12,13]$.

The SU-8 component fabricated following the aforementioned process was used as the master mould and a negative soft mould was produced from it [14]. A widely adopted soft moulding technique is using elastomer PDMS to pattern the micrometer and sub-micrometer sized structures. The PDMS slurry was prepared by mixing the PDMS precursor with a curing agent (Dow Corning Corp. Sylgard 184) in a weight ratio of 10:1 and leaving it for $30 \mathrm{~min}$ to allow the trapped air to escape. The mixture was then poured on the SU-8 master mould template and placed in a vacuum condition until all air bubbles had been removed. Afterwards, it was cured at $65^{\circ} \mathrm{C}$ for 4 hours. After it was cooled to room temperature, the cured PDMS was peeled off from the SU-8 master mould template. Further details about the PDMS moulds can be found in $[15,16]$.

Powder premixing and mould filling. The metallic powders used in the experiments are micron sized $\mathrm{Al}$ powders and nano sized $\mathrm{Cu}$ powders. Table 1 shows the particle sizes, purity, shapes and sources of the powders.

Table. 1. Particle sizes and sources of the powders used.

\begin{tabular}{|l|l|l|l|l|}
\hline Powder & Mean size & Purity & Shape & Source \\
\hline $\mathrm{Al}$ & 2.5 micrometer & $99.9 \%$ & Spherical & Alpoco, UK \\
\hline $\mathrm{Cu}$ & 69.4 nanometre & $99.9 \%$ & Spherical & Shenzhen Junye, China \\
\hline
\end{tabular}

The metallic powder mixture was made of $80 \mathrm{wt} \%$ micron-sized Al powders, $5 \mathrm{wt} \%$ nano-sized $\mathrm{Cu}$ powders and $15 \mathrm{wt} \%$ adhesive binder. The powders and binder were mixed with about $30 \mathrm{ml}$ of acetone to form a slurry. Then the cavity of the patterned PDMS mould was filled up with the slurry using an immersing method [17]. Acetone was gradually evaporated, leaving the slurry dry in the mould. Then the PDMS mould was carefully removed to achieve green components with a good shape retention and relative low porosity level.

Demoulding, sintering and oxidation of green components. Once the slurry was dried, the shaped green component was achieved by peeling off the soft PDMS mould. Next, the moulded 
component was placed inside a furnace(Carbolite 2416-tube furnace) filled with Ar gas and heated to $600^{\circ} \mathrm{C}$ at $5^{\circ} \mathrm{C} / \mathrm{min}$. From previous studies, a 6 hours sintering time at $600^{\circ} \mathrm{C}$ was sufficient to densify this moulded Al- based microcomponent. Detailed studies of the sintering behaviour of the moulded Al-based components can be obtained from the literature[18]. At the end of the sintering cycle, the component was taken out of the furnace and was cooled down to room temperature. The fabricated Al-based microcomponent was then oxidised at $1450^{\circ} \mathrm{C}$ for 70 hours in air. The oxidation of aluminium is described by the reaction Eq. 1 .

$$
4 \mathrm{Al}+3 \mathrm{O}_{2} \rightarrow 2 \mathrm{Al}_{2} \mathrm{O}_{3}
$$

Fig. 1 shows a micro alumina gear that was fabricated following the

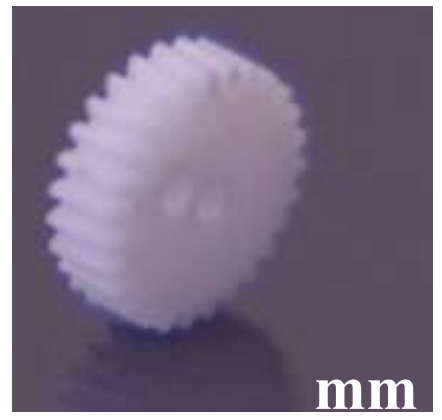

Fig. 1. A alumina microgear. process described above.

\section{Results and discussion}

Image and density analysis. The density of the Al-based and alumina microcomponents have been investigated. Each component was weighed both in air and in distilled water at $10^{\circ} \mathrm{C}$ and the density was calculated. The theory used is based on Archimedes' principle and the equipment used is the Density Determination Kit GX-13 from A\&D Co Ltd. The dimensions of the fabricated mould and microgears are then measured using a micrometer (Mitutoyo, Japan). Table 2 lists the measured density and dimension of each type of microcomponents. The density of alumina component was higher than the pure bulk $\mathrm{Al}_{2} \mathrm{O}_{3}$ density. This may be due to the presence of $\mathrm{Cu}$ in the $\mathrm{Al}_{2} \mathrm{O}_{3}$ structure.

Table. 2. Density and dimension of the microgear.

\begin{tabular}{|c|c|c|c|c|}
\hline Density & Component Density & $\begin{array}{c}\text { Bulk } \\
\text { Density }\end{array}$ & Dimension & *Shrinkage ratio \\
\hline Green component & $2.033 \mathrm{~g} / \mathrm{cm}^{3}$ & $2.70 \mathrm{~g} / \mathrm{cm}^{3}$ & 2.883 & - \\
\hline Sintered component & $2.593 \mathrm{~g} / \mathrm{cm}^{3}$ & $2.70 \mathrm{~g} / \mathrm{cm}^{3}$ & 2.492 & $13.574 \%$ \\
\hline Alumina component & $4.499 \mathrm{~g} / \mathrm{cm}^{3}$ & $3.98 \mathrm{~g} / \mathrm{cm}^{3}$ & 2.822 & $2.045 \%$ \\
\hline
\end{tabular}

${ }^{*}$ Measured outer diameter of microgear.

${ }^{* *}$ Pure bulk $\mathrm{Al}_{2} \mathrm{O}_{3}$ density.

The produced alumina microgears were investigated using SEM (Philips XL30). Fig. 2 illustrates the SEM images on the fractured surface of the alumina microgear with different magnifications. The microstructures of the alumina look uniform and dense from these images.

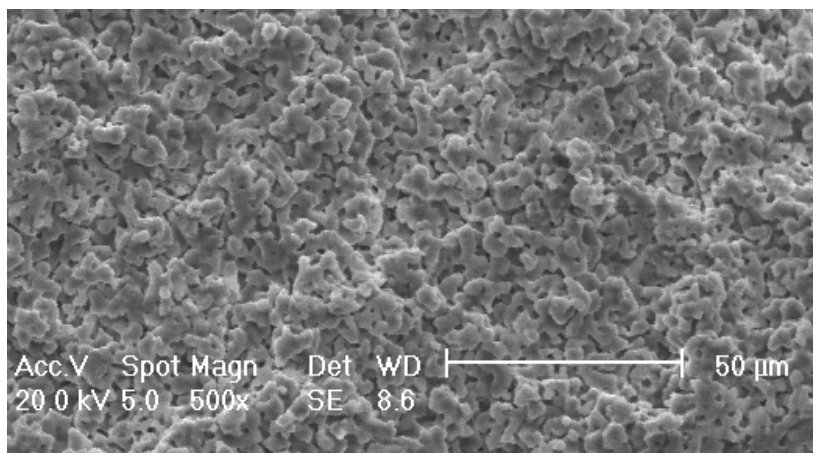

(a)

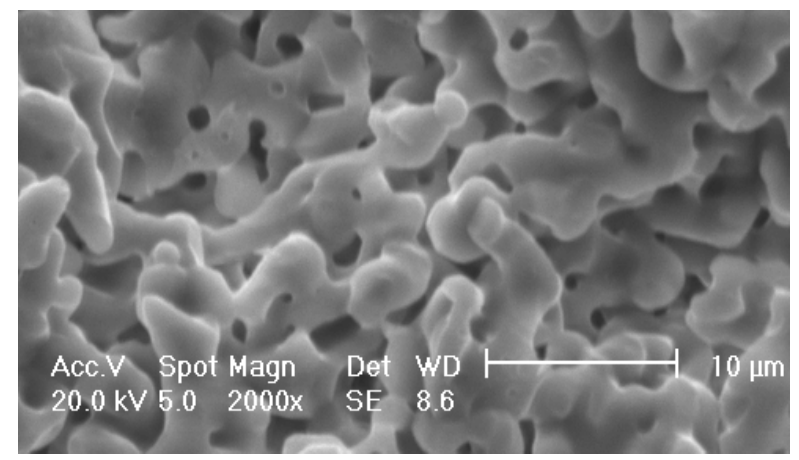

(b)

Fig. 2. SEM images on the fractured surface of the microgears, (a)X500 and (b)X2000. 


\section{Conclusions}

A new fabrication process is presented for producing alumina microcomponents from microsized Al powder and nanosized $\mathrm{Cu}$ powder through combined sintering and oxidation processes. After demoulding and sintering, Al-based alloy microgears have been successfully fabricated with a good shape retention and relatively low porosity level. These microcomponents were then oxidized at $1450^{\circ} \mathrm{C}$. The alumina-based microgears achieved have an overall shrinkage ratio of about $2.0 \%$.

The proposed process shows a way of fabricating three-dimensional alumina microcomponents with little shrinkage while keeping good sintered density. The proposed approach has largely solved the shrinkage problem and eased the way for producing high precision micro ceramic components for wide applications.

\section{References}

[1] L.-A. Liew, W. Zhang, L. An, S. Shah, R. Lou, Y. Liu, T. Cross, M. L. Dunn, V. Bright, J. W. Daily, R. Raj, K. Anseth, "Ceramic MEMS - new materials, innovative processing and future applications", Am. Ceram. Soc. Bull., vol. 80, pp. 25-30, 2001.

[2] W. Eidelloth, W. J. Gallagher, R. P. Robertazzi, R. H. Koch, B. Oh, R. L. Sandstrom, "Wet etch process for patterning insulators suitable for epitaxial high-T superconducting thin film multilevel electronic circuits", Appl. Phys. Lett., 59, 1257-1259, 1991.

[3] F. Rousseau, A. Jain, T. T. Kodas, M. Hampden-Smith, J. D. Farr, R. Muenchhausen, "Lowtemperature dry etching of metal oxides and $\mathrm{ZnS}$ via formation of volatile metal ß-diketonate complexes", J. Mater. Chem., 2, 893-894, 1992.

[4] Van-Hoy, C., Barda, A., Griffith, M. and Halloran, J. W., 'Micro fabrication of ceramics by coextrusion', J. Am. Ceram. Soc., 1998, 81, 152-158.

[5] Wang, S., Li, J.-F., Watanabe, R. and Esashi, M., 'Fabrication of lead zirconate titanate microords for 1-3 piezocomposites using hot isiostatic pressing with silicon molds', J. Am. Ceram. Soc., 1999, 82, 213-215.

[6] Halloran, J. W., 'Freeform fabrication of ceramics', Brit. Ceram. T., 1999, 98, 299-303.

[7] Knitter, R., Bauer, W. and Gohring, D., 'Manufacturing of ceramic microcomponents by a rapid prototyping process chain', Adv. Eng. Mater., 2001, 3, 49-54.

[8] Bourell, D. L., Marcus, H. L., Barlow, J. W. and Beaman, J. J., 'Selective laser sintering of metals and ceramics', Int. J. Powder Metall., 1992, 28, 369-381.

[9] Subramanian, P. K. and Marcus, H. L., 'Selective laser sintering of alumina using aluminium binder', Mater. Manuf. Process., 1995, 10, 689-706.

[10]Bauer, W., Ritzhaupt-Kleissl, H.-J. and Hausselt, J., 'Micropatterning of ceramics by slip pressing', Ceramics International, 1999, 25, 201-205.

[11] U. P. Schonhölzer, R. Hummel, L. J. Gauckler, "Microfabrication of Ceramics by Filling of Photoresist Molds", Adv. Mater., 12, 1261-1263, 2000.

[12] P. Jin, K. C. Jiang, and N Sun, "Ultra-thick SU-8 Fabrication for Micro Reciprocating Engines", Journal of Microlithography, Microfabrication, and Microsystems, Vol 3, No 4, pp 569573,2004

[13] K. Jiang, M.J. Lancaster, I. Llamas-Garro and P. Jin, "SU-8 Ka-Band Filter and

Microfabrication", Journal of Micromechanics and Microengineering, vol 15, pp1522-1526, 2005

[14] C. H. Lee, K. Jiang and G.J. Davies, Surface roughness characterization of silicon and SU-8

microcomponents, Proceedings of Lamdamap 2005 International Conference, pp 402-411,

Cranfield, UK, 2005

[15] H. A. Biebuyck, N. B. Larsen, E. Delamarche, B. Michel, IBM J. Res. \& Dev. 1997, 41, 159.

[16] Zhao, X.-M., Xia, Y. and Whitesides, G. M., Fabrication of Three-Dimensional

Microstructures: Microtransfer Molding, Adv. Mater., vol 8, pp837-840, 1996.

[17] J.-S. Kim, K. Jiang, I. Chang, "A net shape process for metallic microcomponent fabrication using Al and $\mathrm{Cu}$ micro/nano powders", J. Micromech. Microeng. 16 (2006) 48-52. 
[18] J.-S. Kim, I. Chang, K. Jiang, C. L. Falticeanu, Sintering of loosely packed powder mixture of ultrafine Aluminium and nanopowder of $\mathrm{Cu}$ and Sn, Volume 2, Proceedings of EuroPM 2005, 2-5 Oct. pp. $211-216$. 